\title{
Selective reduction in visibility of a posttarget by an identical pretarget masked by noise
}

\author{
TAKASHI MOROTOMI \\ University of Iwate, Morioka 020, Japan
}

\begin{abstract}
The effect of a pretarget (TS1) masked by a noise mask (MS) upon the recognition of a posttarget (TS2) was examined in a TS1-MS-TS2 paradigm. The results clearly showed that the presentation of TS1 masked completely by MS reduced the recognition of a subsequent TS2 to a much greater extent if TS2 was the same as TS1 than when it was not. The results suggest that a TS1 that is perceptually masked by an MS nevertheless continues to have an effect within the visual system. A possible explanation of this reductive effect is described briefly.
\end{abstract}

Two interpretations have been proposed for masking by a noise mask: the integration theory and the interruption theory (Felsten \& Wasserman, 1980; Fox, 1979; Kahneman, 1968; Turvey, 1973).

The integration theory interprets masking as evidence of the limited temporal resolution of the visual system. When target and mask enter within the same processing interval, their images are supposed to be integrated and result in a composite image. Degradation of the target's image thus occurs, and the recognizability or detectability of the target decreases noticeably (Coltheart \& Arther, 1972; Eriksen, 1966; Kinsbourne \& Warrington, 1962a, 1962b; Schultz \& Eriksen, 1977).

The interruption theory interprets masking as the replacement of the target by the mask within the visual information store that is postulated by some information processing models (Averbach \& Coriell, 1961; Averbach \& Sperling, 1961; Sperling, 1963, 1967). The interruption theory assumes that the presentation of a noise mask within a brief interval of the target erases the visual image of target or terminates its processing within the visual system (Haber \& Standing, 1970; Liss, 1968; Sperling, 1964, 1971).

There is much experimental and theoretical evidence that has been interpreted as demonstrating each of these assumptions (Felsten \& Wasserman, 1980; Fox, 1979; Kahneman, 1968; Turvey, 1973).

This paper was written during a Visiting Research Fellowship at the Department of Communication and Neuroscience, University of Keele, from September 1980 to December 1981. The author wishes to thank D. M. MacKay for his kind acceptance of him as a Visiting Research Fellow. The author gratefully thanks Y. Odagiri and A. Saikawa for their invaluable experimental assistance, and V. MacKay and D. H. Foster for a critical reading of the manuscript. The author is also indebted to D. H. Foster and S. Gravano for their considerable assistance with the statistics. The author wishes to thank M. Kanoh, S. Kitajima, and M. J. Musselwhite for their encouragement, and Margaret Hodgson and Hazel Lynch for typing the manuscript.
It is rather surprising, however, that there has so far been no investigation as to whether a target masked by noise has any effect upon the recognition of a stimulus presented after the mask. This point could be crucial for deciding between these two theories of masking. If an internal image of a target is indeed erased or terminated by the presentation of the noise mask, as the interruption theory assumes, then it follows that a target completely masked by noise can have no effect on any further stimulus presented after mask offset. On the other hand, if the target is processed as the composite of target and mask, and the trace of its activity has been sustained in the visual system, as the integration theory supposes, we can expect that some of those aspects of the target preserved within the composite image will have an effect on the processing of a stimulus presented after mask offset. Specifically, we can expect that the detection or recognition of the same target after the noise mask offset will be strongly affected for a certain period of time.

To examine this assumption and investigate the effect upon recognition of the posttarget of the pretarget masked by the noise, we devised the new experimental paradigm of pretarget-mask-posttarget.

\section{EXPERIMENT 1}

The purpose of this experiment was to determine the effect of a pretarget masked by noise upon the recognition of a posttarget stimulus by varying the interstimulus intervals (ISIs) between mask and posttarget stimulus. A nonpretarget condition, forward masking, was employed as a control.

\section{Method}

Subjects. Three students, two females and one male ranging in age from 19 to 21 years, were used as subjects. All had normal or corrected vision.

Stimuli and Apparatus. Thirty Japanese Kana letters were used as pretarget (TS1) and posttarget (TS2). Each Kana letter, composed of $8 \times 5$ rectangular cells, subtended a visual angle of $4 \mathrm{deg}$ 

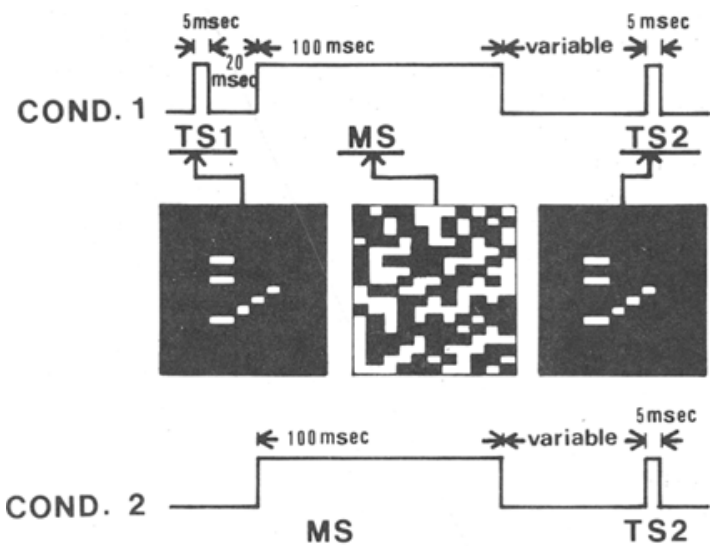

Figure 1. Schematic Illustration of the dioplay sequence, and an example of TS1, MS, and TS2 as used in Experiment 1.

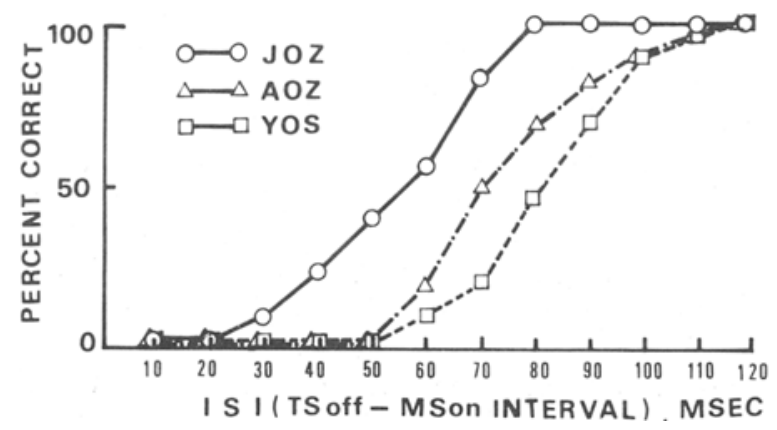

Figare 2. The percentages of correct TS1 tdentification under backward manking are plotted as a function of ISIs between TS1 and MS for each of the three subjects. (e.g., Figure 1). The mask (MS) was a random noise pattern composed of black and white cells of the same size cell as those composing the letters (e.g., Figure 1). The ratio of black to white cells in the random noise pattern was 1:1. The visual angle of the random noise pattern was $14 \mathrm{deg}$. The main part of the random noise pattern is illustrated in Figure 1. Six random noise patterns were prepared, and each random noise pattern was replaced by a fresh random noise pattern every five recognition trials in order to avoid an adaptation effect. The luminances of the light and dark areas of both targets were 3.5 and $.5 \mathrm{~cd} / \mathrm{m}^{2}$, respectively, those of the MS were 10.0 and $1.5 \mathrm{~cd} / \mathrm{m}^{2}$. Stimuli were presented in a four-field tachistoscope in a darkened room.

Procedure. The experiment involved two conditions. In Condition 1, TS1 was presented before MS, but TS1 was completely masked by MS. The same stimulus as TS1 was presented as TS2. In Condition 2, the control condition, a TS1 was not presented before the MS. The TS2 stimuli were the same as those of Condition 1.

The duration of TS1 and TS2 was 5 msec and that of MS was $100 \mathrm{msec}$. The interval between TS1 offset and MS onset in Condition 1 was $20 \mathrm{msec}$. The ISI was chosen on the basis of three subjects' data from a prior backward masking experiment. It had been found that at this ISI the subjects could not detect TS1 (Figure 2).

Under Conditions 1 and 2, the ISIs between MS and TS2 were set to 11 equally spaced values from 20 to $220 \mathrm{msec}$. The four intervals of $100,140,180$, and $220 \mathrm{msec}$ were omitted for one subject. A fixation point consisting of two dots (red) arranged horizontally and subtending $1 \mathrm{deg}$ was presented prior to stimulus presentation.

The presentations at the 11(7) different ISIs in Conditions 1 and 2 were randomized. For each of $660(420)$ recognition trials, the subjects were asked to say what Kana letter they saw.

\section{Results}

In Figure 3, the percentages of correct TS2 identifications under the two conditions are plotted as a function of ISIs between MS and TS2 for each of the three subjects.

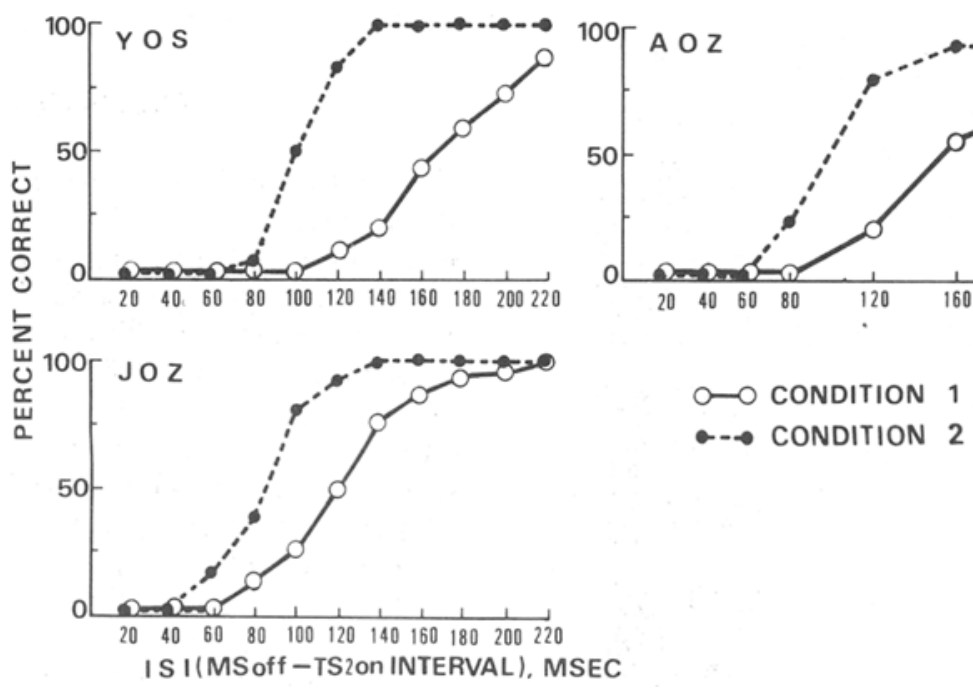

Figure 3. The percentages of correct TS2 Identifications under the two conditions are plotted as a function of ISIs between MS2 and TS2 for each of the three subjects. Condition 1, TS1 was presented before MS. Condition 2, TS1 was not presented before MS. 
Compared with the percentage of correct TS2 identification in Condition 2, that in Condition 1 is significantly lower for all subjects $\left[\chi^{2}(11)=104.8\right.$ and 48.69, p $<.001$ (Subjects Y.O.S. and J.O.Z.); and $\chi^{2}(7)=38.47$, p $<.001$ (Subject A.O.Z.), see Appendix].

These results clearly show that the presentation of TS1 before MS, though it is not seen by subjects, reduces the recognition of the same TS2 as TS1 for about $200 \mathrm{msec}$ after MS offset, or about $320 \mathrm{msec}$ after the presentation of TS1; the reduction of the recognition of TS2 is maximum when the ISI is at 100-140 msec.

\section{EXPERIMENT 2}

The aim of the second experiment was to investigate whether the decrease in recognizability of the posttarget obtained in Experiment 1 depended upon the similarity of the pre- and posttarget stimuli.

For this purpose, three combinations of TS1 and TS2 were employed. First, TS1 and TS2 were the same letter stimulus; second, TS1 and TS2 were different letter stimuli; and third, TS1 had a random pattern stimulus and TS2 had the letter stimulus.

\section{Method}

Subjects. The subjects were two females and one male, ranging in age from 19 to 22 years. One subject had participated in Experiment 1. All subjects had normal or corrected vision.

Stimull and Apparitus. TS1 was selected randomly from the 30 Kana letters in Experiment 1 or from 30 random patterns. The random pattern consisted of the same-sized cells as those composing the letter (e.g., Figure 4). TS2 was chosen randomly from the 30 Kana letters in Experiment 1. The random noise pattern (e.g., Figure 1) used as MS and the apparatus were the same as in Experiment 1.

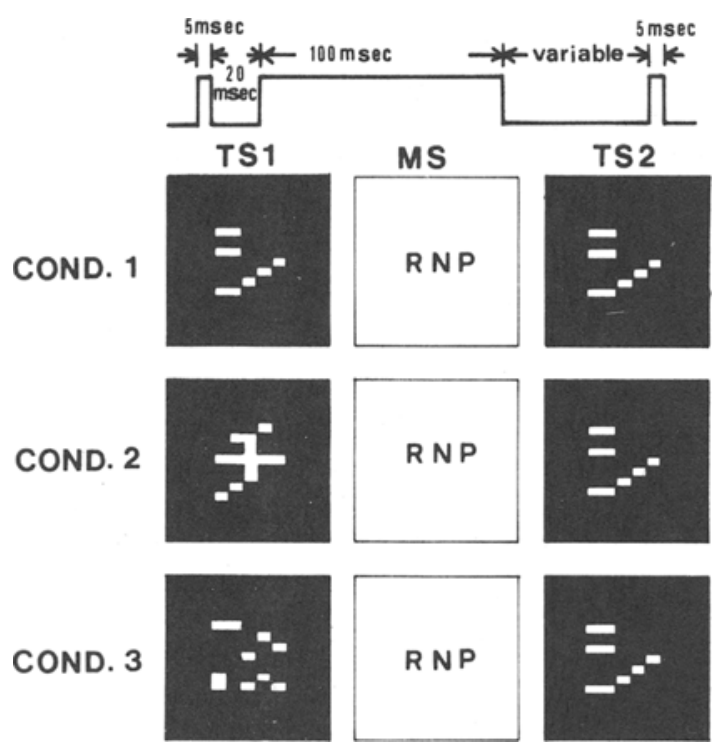

Figure 4. Schematic lilustration of the display sequence, and an exnmple of TS1, MS, and TS2 as used in Experiment 2. RNP = random nolse pattern.
Procedure. The duration of TS1 and TS2 was $5 \mathrm{msec}$ and that of MS was 100 msec. The interval between TS1 offset and MS onset was 20 msec, as in Experiment 1. ISIs of MS and TS2 varied randomly from 40 to $200 \mathrm{msec}$. The fixation point was the two red dots subtending $1 \mathrm{deg}$ and arranged horizontally, as in Experiment 1.

The experiment involved three conditions which were presented in random order. Under Condition 1, TS1 and TS2 were the same letter; under Condition 2, TS1 and TS2 were different letters; under Condition 3, TS1 was a random pattern and TS2 a letter.

The subjects were asked to say what letter they saw. In all, 540 recognition trials ( 3 conditions $\times 6$ ISIs $\times 30$ letters) were performed in random order.

\section{Results}

In Figure 5, the percentages of correct TS2 identifications under the three conditions for each of the three subjects are plotted as a function of ISIs between MS and TS2.

The difference of correct identification of TS2 between Condition 1 and the other conditions was clearly significant for two of the subjects [Subject J.O.Z: $\chi^{2}=25.0, p<.001$ (Conditions 1 and 2), $\chi^{2}=$ 25.6, $\mathrm{p}<.001$ (Conditions 1 and 3); Subject H.O.N: $\chi^{2}(6)=18.2, \mathrm{p}<.01$ (Conditions 1 and 2 ), $\chi^{2}(6)=$ $19.7, \mathrm{p}<.005$ (Conditions 1 and 3), see Appendix] and significant for the third subject in the ISI of 80 msec [Subject T.A.G: $\chi^{2}(1)=8.5, p<.005$ (Conditions 1 and $3, \chi^{2}(1)=5.9, \mathrm{p}<.025$ (Conditions 1 and 2)]. There were no significant differences between Condition 2 and Condition 3 for any subjects $\left[\chi^{2}(6)<1.28\right.$ for all subjects; see Appendix].

The results show clearly that the reduction in recognizability of TS2 occurs maximally when TS1 and TS2 are the same stimulus, and that this reduction lasts for about $160-200 \mathrm{msec}$ after MS offset, or about 280-320 msec after the presentation of TS1.

\section{DISCUSSION}

The major finding in the present experiments is that the presentation of a pretarget TS1, though masked completely by a following mask MS, reduced the recognition of a posttarget TS2 identical to TS1, this reductive effect of TS1 upon the recognition of TS2 lasting for about $200 \mathrm{msec}$ after MS offset, or about $320 \mathrm{msec}$ after the presentation of TS1. In addition, the results in Experiment 2 suggest that the reduction in recognizability of TS2 is determined by the degree of similarity of the TS1 and TS2.

As mentioned above, a criterion for deciding between the integration theory and the interruption theory was whether or not a target completely masked by noise had an effect on a stimulus presented after mask offset. According to this criterion, it might seem that the present results support the integration theory rather than the interruption theory. Many studies on temporal integration have shown that two or more stimuli will be integrated if they 


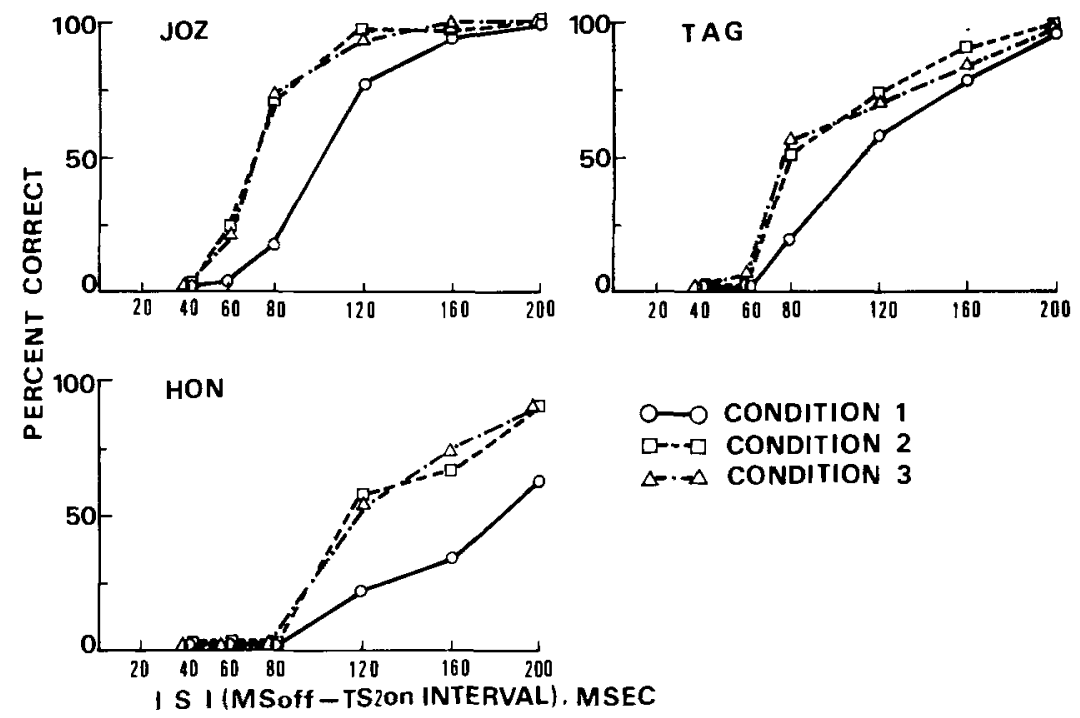

Figure 5. The percentages of correct TS2 Identification under the three conditions are plotted as a function of ISIs between MS and TS2 for each of the three subjects. Condition 1, TS1 and TS2 were the same letter. Condition 2, TS1 and TS2 were different letters. Condition 3, TS1 was a random pattern and TS2 a letter.

are presented within an interval of $100-200 \mathrm{msec}$ (Efron, 1970; Eriksen \& Collins, 1967, 1968; Hogben \& DiLollo, 1974; Morotomi \& Sugawara, Note 1). If the trace of TS1 were sustained in the visual system as the composite of TS1 and MS, it would be reasonable to suppose that summation would occur between TS1 and TS2 and, as a result, that the visibility of TS2 would be increased. However, the presentation of TS1 reduced the recognition of TS2.

How might one explain this counterintuitive result? The results of Experiment 2 show clearly that the reductive effect of TS1 on TS2 depends on the similarity of those two patterns; that is, TS1 affects the recognition of TS2 selectively. This finding suggests the possibility that the reduction in recognition of TS2 might be specifically related to the processing of TS1. Thus, the result of the present experiments might be interpreted as follows. Suppose that MS exerts its effect on the processing of TS1 by inhibiting the activity of the feature analyzers stimulated by TS1. If the second stimulus, TS2, coincides with TS1, then the processing of TS2 by those same analyzers will be impaired. If TS2 does not coincide with TS1, then different analyzers will be involved in its processing and this indirect effect of MS will be less.

This explanation supposes that the feature analyzers activated by TS1 preceding MS are inhibited by the arrival of MS and that this inhibition continues for a certain time after MS offset. The time course of the reductive effect then reflects the recovery process of this inhibition of the feature analyzers stimulated by TS1. Although this expla- nation allows the continuing effect of TS1 after MS, it might be classified as a type of interruption theory rather than integration theory, since the continuing effect of TS1 manifests itself as an inhibition rather than as a facilitation of subsequent stimulus processing.

\section{REFERENCE NOTE}

1. Morotomi, T., \& Sugawara, M. Amplitude changes of visual evoked responses with perceptual fusion and dissolution. I and II. Paper presented at the 42nd Annual Congress of the Japanese Psychological Association, 1978.

\section{REFERENCES}

Averbach, E., \& Coriell, A. S. Short-term memory in vision. Bell Systems Technical Journal, 1961, 40, 309-328.

Averbach, E., \& SpErLING, G. Short-term storage of information in vision. In C. Cherry (Ed.), Information theory. London: Butterworth, 1961.

Colthenrt, M., \& Arthen, B. Evidence for an integration theory of visual masking. Quarterly Journal of Experimental Psychology, 1972, 24, 262-269.

Cox, D. R. The analysis of binary data. London: Methuen, 1970.

Erron, R. The relationship between the duration of a stimulus and the duration of perception. Neuropsychologia, 1970, 8, 37-55.

Eriksen, C. W. Temporal luminance summation effects in backward and forward masking. Perception \& Psychophysics, 1966, 1, 87-92.

Eriksen, C. W., \& Collins, J. F. Some temporal characteristics of visual pattern perception. Journal of Experimental Psychology, 1967, 74, 476-484.

Eriksen, C. W., \& Colnins, J. F. Sensory traces versus the psychological moment in the temporal organization of form. Journal of Experimental Psychology, 1968, 77, 376-382.

Felsten, G., \& Wasserman, G. S. Visual masking: Mechanisms and theories. Psychological Bulletin, 1980, 88, 329-353. 
Foster, D. H. Visual comparison of random-dot patterns: Evidence concerning-a fixed visual association between features and feature-relations. Quarterly Journal of Experimental Psychology, $1978,30,637-654$.

Fox, R. Visual masking. In R. Held, H. W. Leibowitz, \& H.-R. Teuber (Eds.), Handbook of sensory physiology (Vol.8): Perception. Berlin: Springer, 1979.

HABer, R. N., \& Standing, L. G. Direct estimates of the apparent duration of a flash. Canadian Journal of Psychology, 1970, 24, $216-229$.

Hogben, J. H., \& Di Lollo, V. Perceptual integration and perceptual segregation of brief visual stimuli. Vision Research, $1974,14,1059-1069$.

KAHNEmAN, D. Method, findings, and theory in studies of visual masking. Psychological Bulletin, 1968, 70, 404-425.

Kinsbourne, M., \& Warrington, E. K. The effect of an aftercoming random pattern on the perception of brief visual stimuli. Quarterly Journal of Experimental Psychology, 1962, 14, 223234. (a)

Kinsbourne, M., \& Warrington, E. K. Further studies on the masking of brief visual stimuli by a random pattern. Quarterly Journal of Experimental Psychology, 1962, 14, 235-245. (b)

Liss, P. Does backward masking by visual noise stop stimulus processing? Perception \& Psychophysics, 1968, 4, 328-330.

Schultz, D. W., \& Eriksen, C. W. Do noise masks terminate target processing? Memory \& Cognition, 1977, 5, 90-96.

Sperling, G. A. A model for visual memory tasks. Human Factors, 1963, 5, 19-31.

Sperling, G. A. What visual masking can tell us about temporal factors in perception. In Proceedings of the Seventeenth International Congress of Psychology, 1964. Amsterdam: NorthHolland, 1964.

Spenlina, G. A. Successive approximations to a model for shortterm memory. Acta Psychologica, 1967, 27, 285-292.

Sperling, G. A. Information retrieval from two rapidly consecutive stimuli: A new analysis. Perception \& Psychophysics, 1971, 9, 89-91.
TURvey, M. T, On peripheral and central processes in vision: Inferences from an information-processing analysis of masking with patterned stimuli. Psychological Review, 1973, 80, 1-52.

\section{APPENDIX}

The statistical technique used in the analysis of the data is based upon the logistic transform $\log [p /(1-p)]$ of the probability p (Cox, 1970, Sec. 3.4). The empirical logistic transform may be defined as

$$
x(i)=\log \{[r(i)+1 / 2] /[n(i)-r(i)+1 / 2]\},
$$

where $n(i)$ is the number of trials and $r(i)$, the number of successes. The variance at each point is estimated by

$$
v(i)=\{[n(i)+1][n(i)+2]\} /\{n(i)[r(i)+1][n(i)-r(i)+1]\} .
$$

Consider two sets of data (each containing $N$ points), $A$ and $B$, with empirical logistic transforms and estimated variances, respectively, $x_{A}(i), x_{B}(i)$, and $v_{A}(i), v_{B}(i), i=1,2$, $\ldots, N$. Under the assumption that there is no difference between the two sets of data, the quantity

$$
\sum_{i=1}^{n} \frac{\left[x_{A}(i)-x_{B}(i)\right]^{2}}{v_{A}(i)+v_{B}(i)}
$$

is distributed approximately as chi-square with $\mathrm{N}$ degrees of freedom. (For related applications of the logistic transform, see Foster, 1978.)

(Manuscript received March 26, 1981; revision accepted for publication September $18,1981$. ) 